\title{
RMetS
}

Royal Meteorological Society

\section{Model-based estimation of sampling-caused uncertainty in aerosol remote sensing for climate research applications}

\author{
Igor Geogdzhayev, ${ }^{\mathrm{ab} \star}$ Brian Cairns, ${ }^{\mathrm{b}}$ Michael I. Mishchenko, ${ }^{\mathrm{b}}$ Kostas Tsigaridis ${ }^{\mathrm{ab}}$ \\ and Twan van Noije $\mathrm{c}^{\mathrm{c}}$ \\ ${ }^{a}$ Department of Applied Physics and Applied Mathematics, Columbia University, New York, NY, USA \\ ${ }^{\mathrm{b}}$ NASA Goddard Institute for Space Studies, New York, NY, USA \\ ${ }^{\mathrm{c}}$ Royal Netherlands Meteorological Institute (KNMI) Climate Research - Chemistry and Climate, De Bilt, Netherlands \\ ${ }^{\star}$ Correspondence to: I. Geogdzhayev, Columbia University, 2880 Broadway, New York, NY 10025, USA. \\ E-mail: igor.v.geogdzhayev@nasa.gov
}

To evaluate the effect of sampling frequency on the global monthly mean aerosol optical thickness (AOT), we use 6 years of geographical coordinates of Moderate Resolution Imaging Spectroradiometer (MODIS) L2 aerosol data, daily global aerosol fields generated by the Goddard Institute for Space Studies General Circulation Model and the chemical transport models Global Ozone Chemistry Aerosol Radiation and Transport, Spectral Radiationtransport Model for Aerosol Species and Transport Model 5, at a spatial resolution between $1.125^{\circ} \times 1.125^{\circ}$ and $2^{\circ} \times 3^{\circ}$ : the analysis is restricted to $60^{\circ} \mathrm{S}-60^{\circ} \mathrm{N}$ geographical latitude. We found that, in general, the MODIS coverage causes an underestimate of the global mean AOT over the ocean. The long-term mean absolute monthly difference between all and dark target (DT) pixels was $0.01-0.02$ over the ocean and $0.03-0.09$ over the land, depending on the model dataset. Negative DT biases peak during boreal summers, reaching $0.07-0.12$ (30-45\% of the global long-term mean AOT). Addition of the Deep Blue pixels tempers the seasonal dependence of the DT biases and reduces the mean AOT difference over land by $0.01-0.02$. These results provide a quantitative measure of the effect the pixel exclusion due to cloud contamination, ocean sun-glint and land type has on the MODIS estimates of the global monthly mean AOT. We also simulate global monthly mean AOT estimates from measurements provided by pixel-wide along-track instruments such as the Aerosol Polarimetry Sensor and the Cloud-Aerosol LiDAR with Orthogonal Polarization. We estimate the probable range of the global AOT standard error for an along-track sensor to be $0.0005-0.0015$ (ocean) and $0.0029-0.01$ (land) or $0.5-1.2 \%$ and $1.1-4 \%$ of the corresponding global means. These estimates represent errors due to sampling only and do not include potential retrieval errors. They are smaller than or comparable to the published estimate of 0.01 as being a climatologically significant change in the global mean AOT, suggesting that sampling density is unlikely to limit the use of such instruments for climate applications at least on a global, monthly scale.

Key Words: $\quad$ tropospheric aerosols; satellite remote sensing; climate change; aerosol climatology; long-term variability

Received 8 April 2013; Revised 6 November 2013; Accepted 14 November 2013; Published online in Wiley Online Library

\section{Introduction}

The importance of the contribution to climate change by tropospheric aerosols via direct and indirect radiative effects is widely recognized, but its magnitude remains highly uncertain (Hansen et al., 2005; IPCC, 2007; Kiehl, 2007; Loeb and Su, 2010; Lohmann and Ferrachat, 2010; Penner et al., 2011). Satellite observations are expected to provide the climate community with important constraints on the global spatial and temporal distribution of the amount and microphysical properties of aerosols, with the goal of improving modelling accuracy and gaining educated insights into aerosol chemistry and transport. It is therefore of importance to know the accuracy and limitations of global satellite-derived aerosol parameters. Among them the aerosol optical thickness (AOT) is both radiatively important and exhibits large spatial and seasonal variability. Knowing the accuracy of global monthly mean AOT estimates obtained by means of remote sensing would allow for better characterization of the aerosol effects on climate. 


\section{Geogdzhayev et al.}

Based on their spatial coverage, satellite instruments providing information on tropospheric aerosols can be broadly classified into two categories: imagers and along-track sensors. The first category includes the Moderate Resolution Imaging Spectroradiometer (MODIS) (King et al., 2003; Remer et al., 2008; Levy, 2009), the Multi-angle Imaging Spectroradiometer (MISR) (Diner et al., 1998; Martonchik et al., 2009), and Polarization and Directionality of the Earth's Reflectance instrument (POLDER) (Tanré etal., 2011); the second one includes the Aerosol Polarimetry Sensor (APS, failed to launch in March 2011) (Mishchenko et al., 2007; Cairns and Mishchenko, 2012) and the Cloud-Aerosol LiDAR with Orthogonal PolariZation (CALIOP) (Winker et al., 2010). The two instrument classes complement each other from the standpoint of their retrieval capabilities and scientific objectives. The sampling density of imagers allows them to observe localized or rapidly evolving aerosol events and facilitates comparisons with ground-based and in situ measurements. On the other hand, along-track passive sensors (e.g. APS) possess specialized capabilities (such as high-accuracy polarization channels with on-board calibration, wide spectral range and a dense grid of angular views) that are intended to make them highly sensitive to aerosol microphysics (Chowdhary et al., 2005; Cairns et al., 2009; Cairns and Mishchenko, 2012), while active sensors (e.g. CALIOP) are highly sensitive to aerosol vertical distribution (Winker et al., 2010). This complementarity motivated the inclusion of instruments of both types in the A-Train satellite formation.

The minimal set of retrieval requirements for the Glory APS was formulated and discussed by Mishchenko et al. (2004, 2007). It is based on the overall objective to create an advanced global climatology of detailed aerosol and cloud properties that would serve the immediate needs of the modelling and climate communities. The accuracy of individual retrievals of aerosol properties from space-borne observations can be estimated using sensitivity studies (Hasekamp and Landgraf, 2005, 2007; Knobelspiesse et al., 2012) and confirmed by comparison with ground-based and in situ measurements. For a cross-track scanning instrument such as MODIS, individual retrievals may systematically depend on the viewing angle (track number) because of, for example, imperfect choice of aerosol model or surface reflectance model in the retrieval algorithm. Cloud contamination may also be different for different tracks due to possible viewing geometry dependencies of the cloud mask. We will refer to such errors as angular biases. Besides the errors in individual retrievals, the accuracy of the global climatological values derived from the individual measurements will depend on how well the global aerosol field is sampled by a given instrument. The sampling-caused errors have two components: the first relates to sampling frequency and density and is determined by the width of the swath and/or the width of the instrument field of view; the second is caused by the impossibility of or biases in retrievals in certain conditions, such as at low solar elevations, in the presence of clouds, in the sun glint (over ocean), or over bright land surfaces. Depending on geographical and seasonal patterns of aerosols and clouds, the sampling errors of this second type may lead to seasonal biases of the global estimates. In addition, the contributions of the angular biases of individual retrievals and of the sampling errors to the accuracy of global mean estimates are not independent. For example, wide latitudinal belts are excluded for certain MODIS tracks due to the sun glint. The estimated contribution of these areas to the global aerosol mean will then depend on any biases of the glint-free tracks. Similarly the magnitude of the bias due to non-sphericity of dust aerosols will depend on how often they are found over bright surfaces, where reliable retrievals are difficult. The contributions from all these factors will determine how accurately the global aerosol values can be estimated. Bellouin et al. $(2008,2013)$ have suggested that the differences between the satellite-based and model estimates of the direct radiative forcing may in part be due to the incomplete sampling of the total aerosol distribution by satellite instruments.
To take into account such sampling issues, 'satellite simulators' are often used to analyze models and observations in a consistent way (Bodas-Salcedo et al., 2011).

The present study has two main objectives: first, to estimate how sampling affects the accuracy of MODIS-derived global monthly mean AOT; second, to obtain a likely range (lower and upper limits) of errors due to sampling of global mean AOT derived from an along-track remote sensing instrument. These issues are important for climate research because satellite-based aerosol retrievals are often used to constrain aerosols in global circulation models (GCMs) and chemistry transport models (CTMs).

The first issue was studied by Remer et al. (2006), who compared 3 years of contemporaneous data from the two MODIS instruments on board the Terra and Aqua satellites over the ocean and found that long-term global annual mean AOTs agree to within $1 \%$ or 0.0014 . The global monthly mean AOT estimates were found to agree to within a 0.004 root mean square (RMS) difference. However, this study could not take into account the contribution to the global mean AOT of the areas where neither MODIS instrument made retrievals. Kaufman et al. (2000) used Aerosol Robotic Network (AERONET) data to investigate how well the temporal sampling of MODIS Terra and Aqua retrievals represents the daily mean AOT values. They found that the MODIS overpass subsample of the AERONET data represented the annual mean with an accuracy of $2 \%$.

The second issue was addressed by Geogdzhayev et al. (2013), who used single-track subsets of the MODIS Terra Level 2 data to obtain an estimate of 0.0012 over the ocean and 0.0054 over the land for standard errors due to sampling of global monthly mean AOT retrieved by an along-track sampling instrument. The above estimates correspond to an along-track sensor with MODIS-like retrieval capabilities and are likely to be smaller for APS- or CALIOP-like instruments that have additional specialized capabilities. The study concluded that by using the MODIS aerosol data alone, it may not be possible to improve the estimates.

In this article we address the above two issues by combining MODIS Aqua and Terra pixel coordinates with GCM/CTM aerosol data. This approach overcomes the difficulties mentioned above and allows us to calculate sampling errors for the global AOT mean derived from both an imager (e.g. MODIS) and an along-track sensor (e.g. ASP or CALIOP). In the following section we describe the datasets used in the study. Section 3 is devoted to the imager results, and section 4 deals with along-track sampling estimates.

\section{Data}

The MODIS level 2 aerosol dataset is an instructive choice for this study because this instrument has a wide swath yielding global coverage every one or two days. The MODIS AOT data have been thoroughly characterized (e.g. Chýlek et al., 2005; Ichoku et al., 2005; Remer et al., 2005; Zhang and Reid, 2006; Kahn et al., 2009; Mishchenko et al., 2009, 2010; Xiao et al., 2009; Levy et al., 2010; Shi et al., 2011, 2013; Schutgens et al., 2013), in particular by comparing them with ground-based AERONET measurements (Holben et al., 1998; Dubovik et al., 2002), and have been used extensively in aerosol research.

For our analysis, we use geographical coordinates of the MODIS Terra and Aqua Collection 5.1 level 2 AOT data separately over land and ocean. We consider the period from 2003 through to 2008. The data have a native resolution at nadir of $10 \mathrm{~km}$. We will refer to these individual aerosol retrievals as 'MODIS pixels'. They should not be confused with the original detector radiance measurements with a $500 \mathrm{~m}$ resolution at nadir. Each crosstrack scan consists of 135 pixels. Many passive remote sensing instruments on a Sun-synchronous orbit, including MODIS, do not provide reliable retrievals under large solar zenith angles. As a consequence, their useful coverage represents a wide belt of geographical latitudes that seasonally shifts to the north during the boreal summer and to the south during the boreal winter. 

rescaling (see text).

\begin{tabular}{|c|c|c|c|c|c|c|c|}
\hline & \multirow[t]{2}{*}{ Version } & \multicolumn{2}{|c|}{ Resolution } & \multicolumn{2}{|c|}{ 2003-2008 global mean AOT over ocean ${ }^{a}$} & \multicolumn{2}{|c|}{ 2003-2008 global mean AOT over land } \\
\hline & & Latitude & Longitude & Original & Rescaled & Original & Rescaled \\
\hline GISS & Model E & 2 & 2.5 & 0.384 & 0.134 & 0.570 & 0.199 \\
\hline GOCART & 4 & 2 & 2.5 & 0.109 & 0.133 & 0.228 & 0.279 \\
\hline SPRINTARS & 384 & 1.125 & 1.125 & 0.0876 & 0.134 & 0.155 & 0.229 \\
\hline TM5 & 3 & 2 & 3 & 0.082 & 0.134 & 0.159 & 0.261 \\
\hline
\end{tabular}

${ }^{\mathrm{a}} 2003-2007$ for GOCART.

This also implies that the ratio of the number of pixels in which retrievals are made to the total number of available pixels at higher latitudes has a strong seasonal dependence. For example, in 2003 the number of all MODIS Aqua over-ocean pixels below $60^{\circ} \mathrm{S}$ varied between around 6\% (June) and 18\% (December) of the total number of over-ocean pixels in those months, while the number of actual retrievals changed from 0 to $3 \%$ only. To limit these two effects, which may lead to spurious seasonality, below we only consider pixels with geographical latitudes between $60^{\circ} \mathrm{S}$ and $60^{\circ} \mathrm{N}$. For consistency we apply these geographical limits to the model data as well. Note that for brevity we will call 'global' the mean values calculated for latitudes between $60^{\circ} \mathrm{S}$ and $60^{\circ} \mathrm{N}$.

Model aerosol fields are readily available (Schulz et al., 2006). Models can provide AOT fields with a daily or finer temporal sampling and a spatial sampling that is finer than the Equator ground-track spacing of the A-Train $\left(1.6^{\circ}\right)$. The combined usage of the MODIS level 2 aerosol pixel coordinates and model AOT fields provides a test bed where the 'true' AOT values are exactly known everywhere around the globe. This allows us to estimate AOT in places where it was 'retrieved' by the instrument and those where it was not, and to calculate biases in the global mean. Considering model AOT fields is also useful for estimation of global mean sampling-caused errors by an along-track instrument. Indeed, substituting model AOT fields for actual MODIS retrievals eliminates any spurious dependence of the retrieved AOT on the track number (angular biases). Furthermore, by studying single-track subsamples of all MODIS pixels or of the pixels in which actual retrievals were made, we can model an ideal virtual along-track instrument capable of retrieving aerosol everywhere (former case) or a virtual instrument with MODIS-like capabilities and limitations (latter case). These two cases can provide the lower and upper bounds respectively on the sampling-caused errors of an along-track sensor. We may expect the upper estimate to be closer to that obtained by Geogdzhayev et al. (2013) by directly resampling the actual retrieved MODIS AOT field. We may also expect the actual sampling-caused errors of instruments such as APS and CALIOP to lie somewhere in between those bounds. The knowledge of the upper and lower bounds is important for evaluating the capabilities of future space missions to estimate global AOT.

In what follows we use daily AOT fields from four models for the period 2003 through 2008*: Goddard Institute for Space Studies (GISS), Global Ozone Chemistry Aerosol Radiation and Transport (GOCART), Spectral Radiation-transport Model for Aerosol Species (SPRINTARS) and Transport Model 5 (TM5). All model data runs were part of Phase II of the Aerosol Comparison between Models and Observations (AeroCom) (Kinne et al., 2006; Schulz et al., 2009). Table 1 lists the version numbers and spatial resolutions of the models. The spatial resolution varies between $1.125^{\circ} \times 1.125^{\circ}$ for SPRINTARS and $2^{\circ} \times 3^{\circ}$ for TM5. Details on the treatment of aerosols in the models may be found in Takemura et al. (2005) and Myhre et al. (2013).

Long-term average aerosol amounts differ significantly for different models (see Table 1). To make the datasets comparable, we have renormalized model AOT values by requiring that the

*2003-2007 for GOCART. long-term mean average model AOT over ocean be equal to the mean MODIS Aqua-derived value. For each model the same renormalization coefficient was applied to all data values over ocean and over land for the entire period considered in this study. We chose to use the MODIS mean AOT over the ocean because (i) the data volume is significantly larger over ocean than over land and (ii) MODIS retrievals are estimated to be more accurate over ocean than over land (Remer et al., 2008). We preferred to use the Aqua- rather than Terra-derived mean because of the MODIS Terra calibration problems, specifically the issue of response versus scan (RVS) that may have affected AOT retrievals in Collection 5 (Meister et al., 2012). This effect is estimated to be much smaller in the MODIS Aqua data and is going to be rectified in Collection 6. As the same renormalization coefficient was used for the data over land as for the data over ocean for each model, the long-term mean AOTs over land differ for different models but make the results over ocean and land consistent for any given model. The results of this study are expressed as absolute and relative errors and biases. Rescaling has a straightforward effect on these results: it simply introduces a multiplicative factor for the absolute errors and does not affect the relative errors (e.g. an increase of the global monthly mean AOT by $10 \%$ will increase absolute error estimates by $10 \%$ and will not change the relative errors). In rare cases model aerosol datasets may contain unrealistically high AOT values. For example, some SPRINTARS values can exceed 30 . We have removed these values by limiting the maximum AOT value to 3 for any grid cell. Fewer than $0.1 \%$ of SPRINTARS data points and fewer than $0.01 \%$ for other models were affected.

Figure 1 shows long-term mean AOT maps for the MODIS Aqua and Terra datasets as well as for the four model datasets. It can be seen that there is a qualitative similarity in the basic structure of the fields, with many common large-scale features, such as large aerosol loads over northern and central Africa as well as over southern and eastern Asia. Significant differences exist, however, between the different models and between models and satellite instruments in terms of the magnitude of these features. For example, the GISS model shows a prominent AOT increase in the Southern Ocean, whereas almost no such increase is seen in the TM5 data. Similar to Figure 1, the dependencies of the model- and satellite-derived long-term mean AOT on the geographical latitude shown in Figure 2 are qualitatively similar. Over ocean they are characterized by increases over the Southern Ocean, north of the Equator due to Saharan dust outflows, and in the belt between $30^{\circ} \mathrm{N}$ and $40^{\circ} \mathrm{N}$ affected by the Asian dust. The magnitude of these features varies significantly from model to model. Over land, GOCART and TM5 show significantly larger increases at $10^{\circ} \mathrm{N}$ than SPRINTARS and GISS as well as MODIS Aqua and Terra means. We will not attempt to explain the reasons for the differences in the aerosol fields for different models shown in Figures 1 and 2, but instead we will use these fields to obtain an ensemble of the estimates of the accuracy of the global mean AOT derived from MODIS data.

Our approach is to calculate the global monthly mean AOT values using the geographical coordinates of the MODIS pixels. However, instead of using the actual retrievals, we determine the AOT value for each pixel by bilinear interpolation of the model aerosol AOT field using the actual coordinates of that pixel. This 
(a)

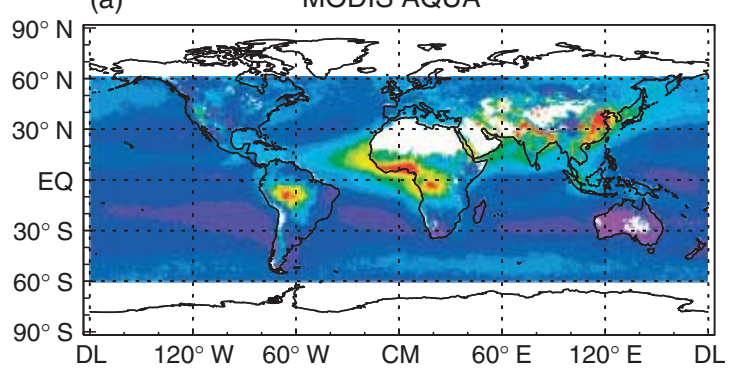

(c)

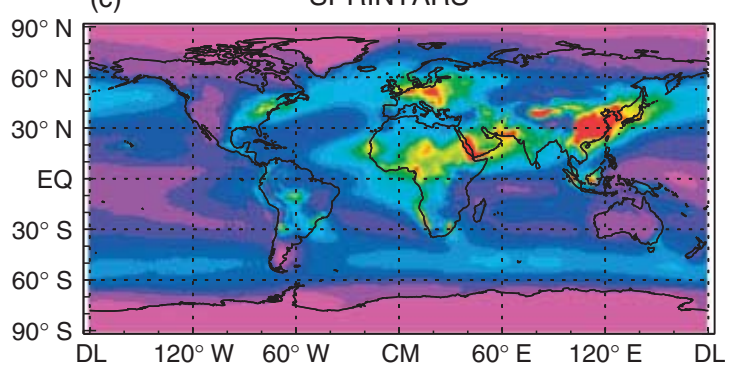

(e)
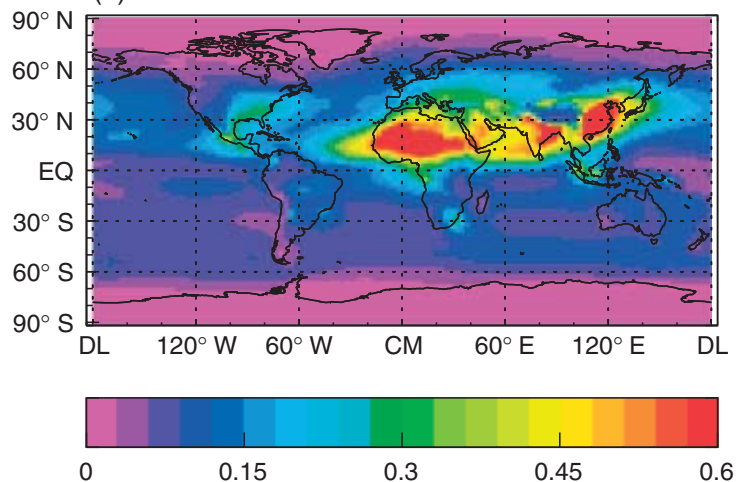

(b)

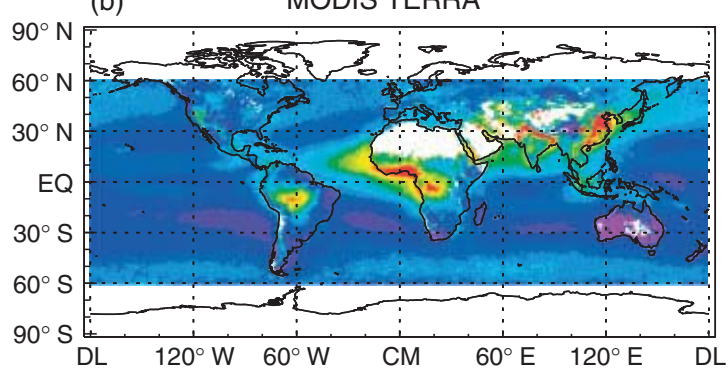

(d)

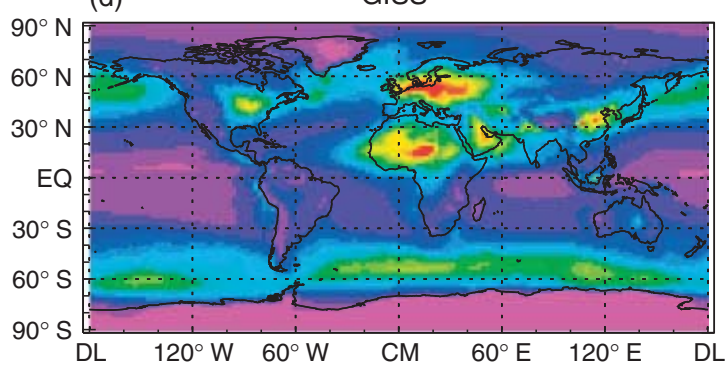

(f)
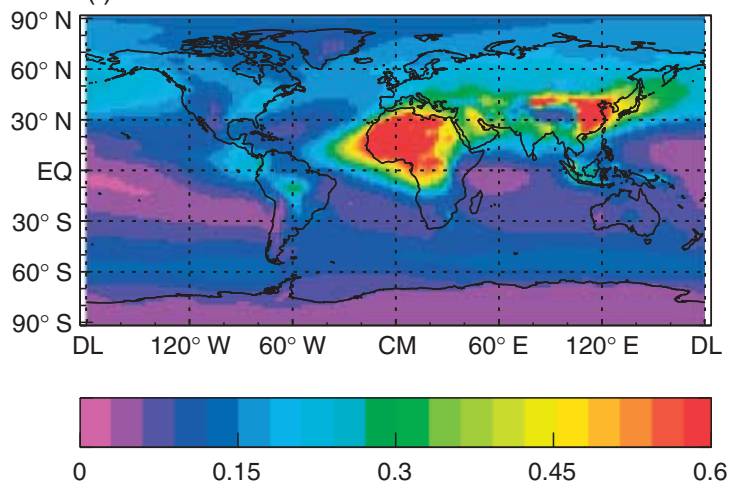

Figure 1. (a-e) Mean aerosol optical thickness (AOT) at $550 \mathrm{~nm}$ for January 2003 to December 2008. (f) Mean AOT at $550 \mathrm{~nm}$ for January 2003 to December 2007. Model data have been rescaled to match the corresponding long-term global MODIS Aqua mean over ocean.

procedure may be thought of as flying the MODIS instruments virtually over the model aerosol field.

A number of aerosol reanalysis products have become available over recent years, such as the Modern Era Retrospective-analysis for Research and Applications (da Silva et al., 2012), the Monitoring Atmospheric Composition and Climate (MACC) (Inness et al., 2013) and Navy Aerosol Analysis and Prediction System (Zhang and Reid, 2006). Although for many applications they are superior to the simple approach adopted here, we find reanalysis products to be less suited for the purpose of estimating the accuracy of the global mean AOT from the MODIS. This is because all these products are based on the assimilated MODIS AOT fields. This dependence makes it difficult to attribute the accuracy estimate to either the MODIS performance or to the specificity of the reanalysis fields. To avoid this circular logic problem, we chose to consider several independent aerosol model datasets and to obtain an ensemble of accuracy estimates.

This approach allows us to obtain self-consistent estimates of what would be the retrieved values, not only where the actual MODIS retrievals exist, but also in the areas where the retrievals could not be made (because of low solar elevation, clouds, surface type, sun glint, high aerosol loads, etc.). Intraday variability of aerosol distributions, which is not considered in this study, may affect sampling as well.

To evaluate the effect of reduced sampling of an along-track instrument, we also subsample MODIS pixels into longitudinal and latitudinal tracks following the approach proposed by Geogdzhayev et al. (2013) and summarized below.
We partition MODIS pixels into two groups. The first group is comprised of 135 sets, each containing only pixels corresponding to a specific MODIS longitudinal track number. These sets may be thought of as being produced by 135 virtual alongtrack instruments, each collecting its own data and simulating the pixel-wide along-track spatial sampling of a CALIOP- or APS-like instrument. The second group consists of 135 sets of data obtained by dividing all MODIS cross-track scans into sequential 135-scan segments, numbering cross-track scans in each segment by assigning numbers between 1 and 135, and retaining in each set only the pixels with a specific scan number from all segments. This second group emulates 135 socalled 'latitudinal-track' instruments that make measurements by scanning perpendicularly to the satellite vector of motion the same way the MODIS does. However, each of them is 'turned on' only for a short period of time to collect just one cross-track scan of the MODIS data from each 135-scan segment. Figures 1 and 2 in Geogdzhayev et al. (2013) show explicit diagrams of the two partitioning methods. The longitudinal and latitudinal subsamples are similar in size and statistically equivalent. The difference between the two subsampling approaches becomes apparent if angular biases are present in the original imager retrievals. Such biases would increase the differences between any two longitudinal subsamples above the levels caused by the natural variability of aerosol fields. On the other hand, all latitudinal samples will be similarly affected because each viewing direction's statistical weight is the same for all subsamples. 

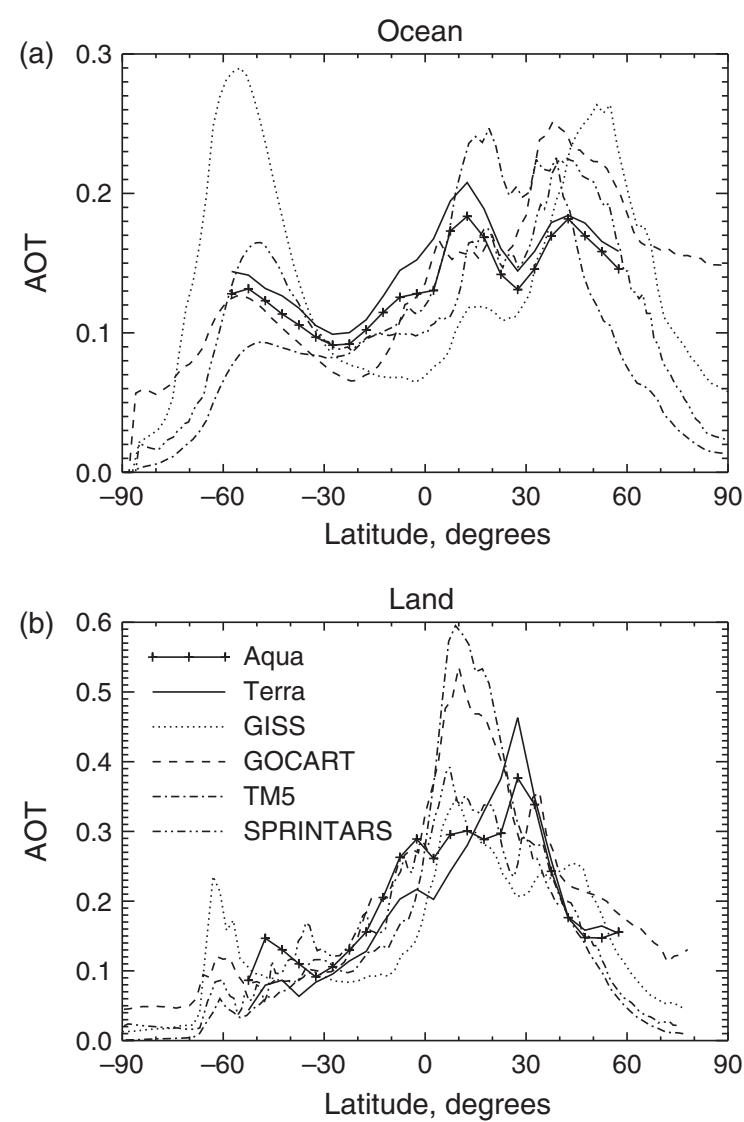

Figure 2. Mean aerosol optical thickness (AOT) over ocean (a) and over land (b) as a function of geographical latitude for MODIS Aqua and Terra and the models listed in Table 1. All curves except those for GOCART correspond to the period from January 2003 to December 2008, whereas the GOCART curves are for January 2003 to December 2007.

\section{Imager results}

First, we consider the idealized case in which AOT values are available for every geolocated MODIS pixel. This corresponds to a situation where the instrument makes an exact aerosol retrieval regardless of the presence or absence of clouds and of specific surface conditions. We then compare global monthly mean AOT values calculated separately for the actual MODIS Terra and Aqua pixels. The two means will differ because the geographical coordinates of the MODIS Aqua and Terra pixels over any region, and therefore the corresponding AOT values, will be different. We used the surface-type mask included in the MODIS level 2 product to differentiate between land and ocean pixels. To achieve a better separation of the land and ocean sets, coastal pixels were excluded from the analysis. The results are shown on Figure 3(a) with coloured dashed curves using the SPRINTARS model dataset. We find that over the 6 year period the monthly mean AOTs 'retrieved' by the two instruments agree to within 0.00066 over land and 0.0002 over ocean in terms of the mean absolute difference. It should be noted that because we use daily model AOT values (hence the diurnal cycle is not considered) and because both Terra and Aqua follow the same orbit of the A-Train satellite constellation, their coverage in this idealized case should be very similar. We therefore ran an additional test where we offset the longitude of all Aqua pixels by $12^{\circ}$, roughly half the distance between two successive Equator crossings. This models the two MODIS instruments but on different orbits. Similar absolute differences in the global monthly mean AOT were observed. In this idealized case we found the differences to be much smaller than those in the more realistic cases presented below, thereby suggesting that the density of the full MODIS sampling is sufficient for the estimation of the global AOT within the restriction on the latitude imposed in this study and that its effects on the accuracy of the real-world results may be disregarded.

Figure 3(a) also shows the calculated global monthly mean AOT for the pixels where actual retrievals were made (solid coloured curves; the model values were still used instead of the actual ones). We use the MODIS pixels with a quality flag value of 3 over land and greater than 0 over ocean. We will call them 'Dark Target' (DT) pixels for short. Compared with the all-pixel case, the mean absolute monthly differences between the two instruments increased to 0.0011 over ocean and to 0.011 over land. The larger increase over land reflects the higher variability of aerosols there compared with the open ocean case. It may also reflect seasonal DT biases, which are discussed later in this section. For comparison the figure also shows the differences between the MODIS Aqua- and MODIS Terra-retrieved global monthly means over land (solid black curve) and over ocean (dashed black curve). Over land the real and model DT data differences show very similar magnitude and seasonality, and the over-ocean model produces less variability than the MODIS retrievals, which may be due to the unaccounted diurnal cycle or the smoothness of the model data over ocean. The systematic difference between the Aqua and Terra global means of about 0.01 over ocean is similar to that reported in Remer et al. (2008).

Small-scale AOT variability cannot be accounted for by using model data because the model grid-cell size is too coarse compared with the resolution of the MODIS level 2 product ( $10 \mathrm{~km}$ at nadir). In order to investigate the influence of such variability, we ran tests in which model data were perturbed using the following procedure. We subdivided each $1.125^{\circ} \times 1.125^{\circ}$ SPRINTARS grid cell into $10 \times 10$ subcells forming a checker pattern with alternating 'light' and 'dark' squares. We then subtracted $30 \%$ of the mean AOT value of the original grid cell from the MODIS pixels with coordinates falling into the 'dark' subcells and added $30 \%$ of the mean AOT for pixels in the 'light' subcells. In addition, the same test was run with the perturbation of $50 \%$ of the cell AOT. Although this simple procedure does not pretend to reproduce the real small-scale aerosol variability, it has the advantage of preserving the mean cell AOT values, thereby allowing us to simulate the effects of subcell AOT variability on global means. The assumed perturbation amount is several times larger than the variability observed from the MODIS and ground-based sunphotometers for background aerosols over land and ocean at comparable scales (Alexandrov et al., 2003, 2004). We found that even for the extreme case of the $50 \%$ perturbation (100\% of the mean AOT subcell gradient), the global mean AOT differences between the standard and perturbed cases did not exceed $0.04 \%$ over ocean and $0.1 \%$ over land. These results are expected. For the small scale variability to influence global mean estimates, it has to correlate with the instrument's sampling pattern. Given the random nature of such variability this is highly unlikely.

Figure 3(b) displays the time series of global monthly mean AOT for the MODIS Aqua (solid curves) and Terra (dashed curves) for the all- and DT-pixel scenarios over ocean using the SPRINTARS AOT dataset. Also shown are the means calculated using DT-complementary sets (i.e. where actual retrievals were not performed). The time-series for the two MODIS instruments are very similar. Over ocean the mean calculated from the DT pixels is systematically lower than the mean for all pixels, whereas the value for the complementary set is always higher. The mean absolute difference between the DT-pixel and all-pixel means for the two instruments is around 0.018. Using the Aqua pixel coordinates, we repeated the calculations for the GISS, GOCART and TM5 models (not shown). We found a similar systematic negative bias of DT pixels for the GISS and GOCART models with mean absolute differences of 0.02 and 0.015 , respectively. The TM5 model shows alternating periods of negative and positive bias so that the mean absolute difference for this model is smaller at 0.01 . Based on the 6 years of data from Figure 3(b) for SPRINTARS and similar time series for the GISS, GOCART and TM5 models, we calculated the mean signed differences for each 
(a)

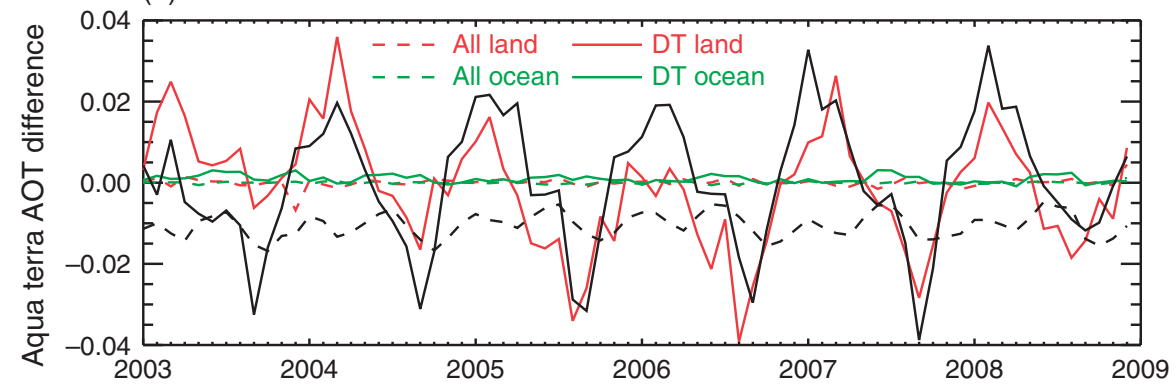

(b)
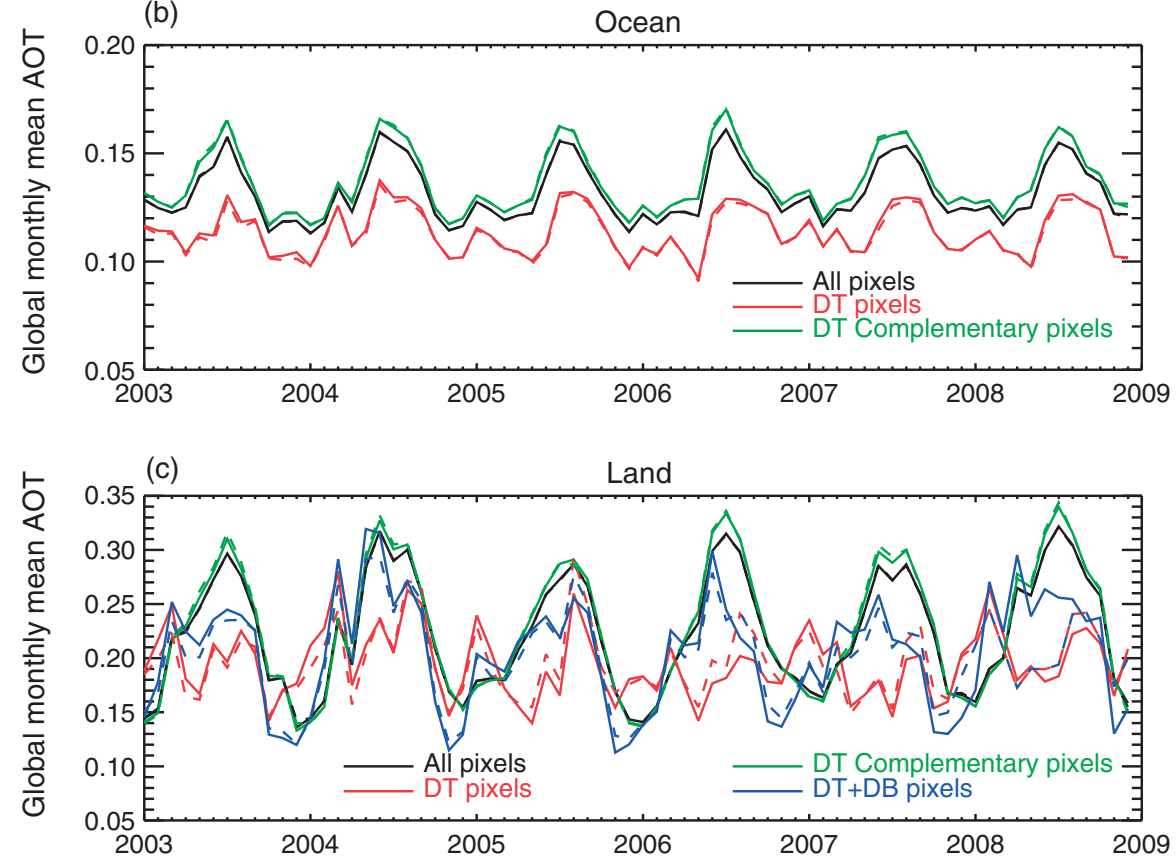

(d)

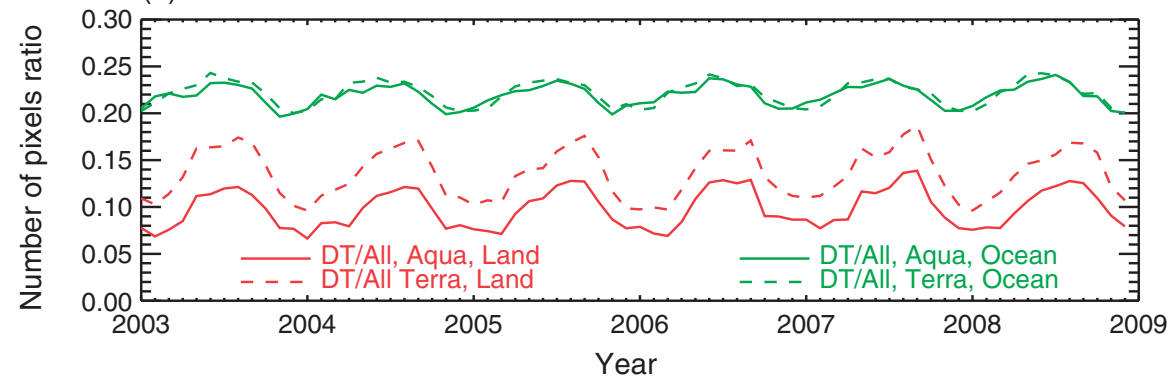

Figure 3. (a) Differences in the global monthly mean aerosol optical thickness (AOT) over land (red) and ocean (green) between MODIS Aqua and MODIS Terra pixels computed using the synthetic dataset based on the SPRINTARS AOT data. Solid coloured curves correspond to the dark target pixels, dashed curves correspond to all pixels. Also shown are the differences in the global monthly mean AOT over land (solid black) and ocean (dashed black) between the actual MODIS Aqua and MODIS Terra retrievals. (b) Time series of the global monthly mean AOT over ocean for all pixels (black), Dark Target (DT) pixels (red), and a set of pixels complementary to DT (green). The synthetic dataset is based on the SPRINTARS AOT data. The solid (dashed) curves correspond to MODIS Aqua (Terra) data. (c) Time series of global monthly mean AOT over land for all pixels (black), DT pixels (red) and DT + DB pixels (blue). The synthetic dataset is based on the SPRINTARS AOT data. The solid (dashed) curves correspond to MODIS Aqua (Terra) data. (d) Time series of the ratio of the monthly number of DT pixels to the total monthly pixel number over land (red) and ocean (green). The solid (dashed) curves are for MODIS Aqua (Terra).

month of the year. The results for the MODIS Aqua pixels are shown in Figure 4 by solid curves. The SPRINTARS panel of Figure 4 also displays the results for the MODIS Terra (dashed curves). Monthly variability is shown as uncertainty regions. The dependencies for the MODIS Aqua and Terra agree to within the uncertainty levels. It can be seen that all four models show a similar seasonal dependence of the difference between all-pixel and DT-pixel cases with a negative bias $\sim 0.03$ for GISS, GOCART and SPRINTARS and $\sim 0.015$ for TM5 in the boreal summer (lefthand axes of Figure 4(a) and (c)). Relative to the long-term global mean AOT (right-hand axes), the negative bias is $\sim 10 \%$ for
TM5 and over $20 \%$ for other models. The smallest bias, less than 0.01 , is observed in the spring and autumn for all models; it increases somewhat in boreal winter, especially for the GISS model. Although the model aerosol fields differ significantly from each other and from the satellite-retrieved ones (cf. Figures 1 and 2 ), the similarities between the seasonal differences suggest that the MODIS instruments may underestimate the global monthly means by similar amounts, especially during boreal summers.

Figure 5(a) and (b) show the AOT probability density functions for all-pixel (solid curves) and DT-pixel (dotted curves) scenarios using the SPRINTARS data over the ocean. It can be seen that for 

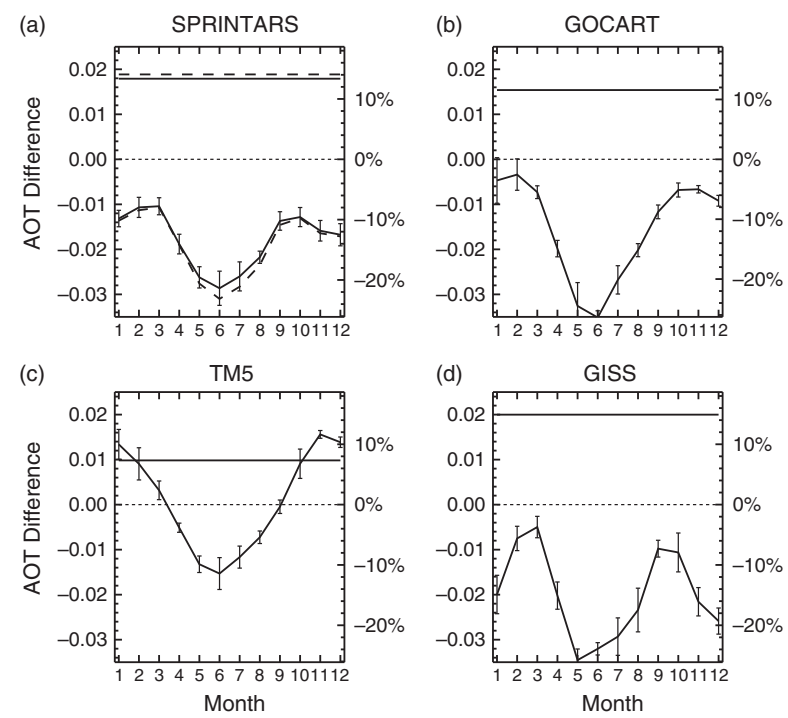

Figure 4. Signed differences of the global monthly mean aerosol optical thickness (AOT) over ocean. The curves represent the DT-pixel mean minus the all-pixel mean for MODIS Aqua for the synthetic dataset based on the (a) SPRINTARS, (b) GOCART, (c) TM5 and (d) GISS model AOT data. Solid horizontal lines represent the long-term mean absolute differences between the all-pixel and DT-pixel sets. Dotted horizontal lines mark zero bias. The left-hand scale for each panel is for the absolute AOT difference, the right-hand scale is for the AOT differences normalized by the rescaled global mean AOT values over ocean from Table 1.
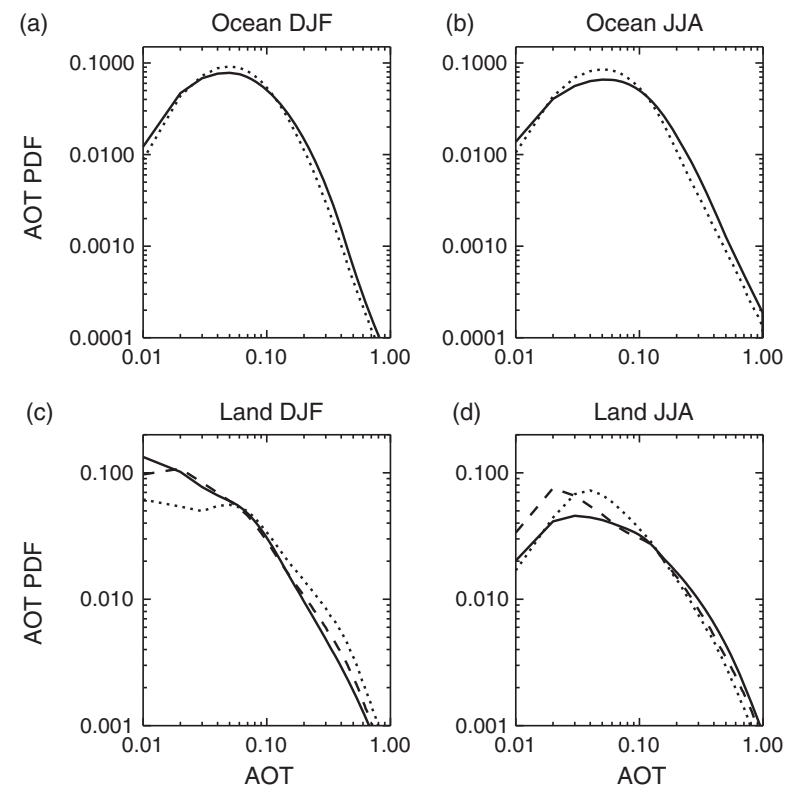

Figure 5. Aerosol optical thickness (AOT) probability density functions ((a) and (b)) over ocean and over land ((c) and (d)) for((a) and (c)) December, January, and February and ((b and (d)) June, July, and August computed using the SPRINTARS model dataset. Solid curves are for all pixels, dotted curves are for DT pixels, and dashed curves are for DT + DB pixels of MODIS Aqua.

both December, January, February (DJF; (a) and (c)) and June, July, August (JJA; (b) and (d)), pixels with AOT $>0.2$ occur less frequently for the DT dataset, consistent with the overall negative bias. Interestingly, DT pixels with very small AOTs of less than 0.02 are also less frequent.

We can suggest two possible explanations for the negative DT bias in boreal summer. One may be the geographical effect of the sun glint. The MODIS algorithm does not perform aerosol retrievals within $40^{\circ}$ of the sun glint direction. In the summer, higher AOT values are found in the northern Tropics compared with the Southern Hemisphere oceans owing to dust outflows (cf. Figure 2). At the same time the tropical regions have the
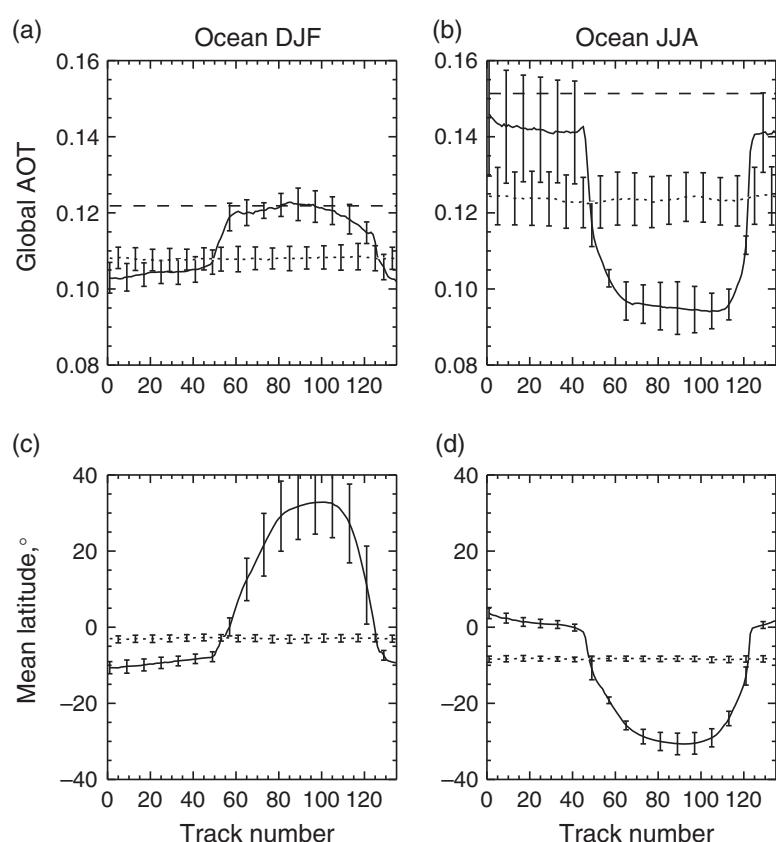

(d)

Figure 6. ((a) and (b)) Seasonal global mean aerosol optical thickness (AOT) as a function of the MODIS Aqua track number for the synthetic dataset based on the SPRINTARS model AOT data over ocean: (a) and (c) are for December, January, and February; (b) and (d) are for June, July, and August. The dashed horizontal lines indicate the 'true' AOT level calculated using all MODIS Aqua pixels. Solid lines are for longitudinal tracks, dotted lines are for latitudinal tracks (DT pixels). ((c) and (d)) Mean latitude of DT pixels for longitudinal (solid curves) and latitudinal (dotted curves) tracks. The vertical bars indicate month-to-month variability.

highest solar elevations, resulting in proportionally more pixels being excluded from retrieval due to the glint condition. This leads to the reduced contribution of high aerosol load areas to the global mean. This hypothesis is corroborated by Figure 6 showing the long-term global mean AOT calculated using DT pixels of a given MODIS longitudinal track (see the previous section for the longitudinal and latitudinal partitioning description) as a function of the track number ((a) and (b), solid curves). Dashed lines indicate the 'true' AOT level, calculated using all MODIS pixels. Longitudinal tracks with numbers between 45 and 125 experience sun-glint conditions for some latitudes while other tracks never see the sun glint. One can see that although DT AOT means are below the all-pixel level for all tracks, the negative bias for the glint-affected tracks varies greatly between the DJF (a) and JJA (b) periods while remaining stable for the glint-free tracks. The reason for this seasonality becomes apparent upon examination of Figure 6(c) and (d) which show the mean latitude of the DT pixels of each longitudinal track (solid curves) for the two seasons. The mean latitude for the glint-affected track can change by more than $60^{\circ}$ between summer and winter, meaning that the AOT 'retrievals' for these tracks come from completely different parts of the ocean.

The second explanation for the negative DT bias in boreal summer may be the cloud screening artefacts, by which two effects are possible. Clouds may be more frequent in areas with high AOTs (e.g. tropics) or high aerosol load pixels may be more likely to be misclassified as cloudy compared with small-AOT pixels. The net effect in both cases is the underrepresentation of high-aerosol-load pixels in the global mean. Further research is necessary to evaluate the relative contribution to the overall bias caused by these or other mechanisms.

Over land, Figure 3(c), the relationship between the global mean $\mathrm{AOT}$ values obtained using the DT and all pixels differs from the one over ocean. For the four models considered, the phase and/or magnitude of the seasonal dependence shows significant discrepancies between the all-pixel and DT-pixel sets. As a result, the long-term average absolute monthly difference between the 

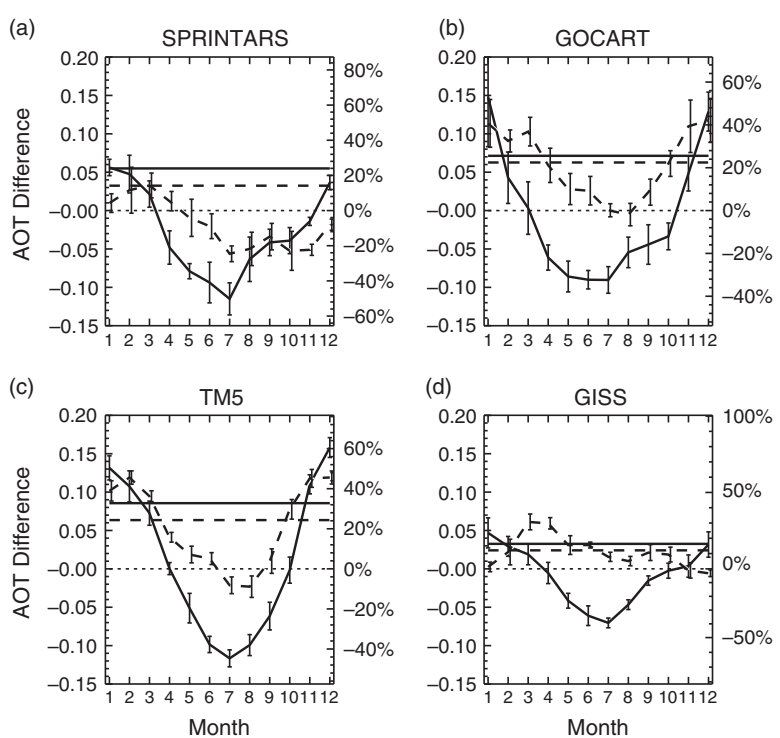

Figure 7. Signed differences of the global monthly mean aerosol optical thickness (AOT) over land. The solid curves represent the DT-pixel mean minus the all-pixel mean. The dashed curves represent the DT + DB-pixel mean minus the all-pixel mean. MODIS Aqua pixels for the synthetic dataset based on (a) SPRINTARS, (b) GOCART, (c) TM5 and (d) GISS model AOT data. Horizontal lines represent mean absolute differences between the all- and DT-pixel sets (solid) and between all- and DT + DB-pixel sets (dashed). Dotted horizontal lines mark zero bias. Left-hand scale for each panel is for the absolute AOT difference, the right-hand scale is for the AOT differences normalized by the rescaled global mean AOT values over land according to Table 1.

two cases over land is higher than that observed over ocean: 0.033 (GISS), 0.07(GOCART), 0.05 (SPRINTARS) and 0.087 (TM5). This is also true in the relative sense, taking into account the higher mean global AOT over land. The larger differences over land may be expected given the smaller data sample and the more difficult retrieval conditions. Figure 7 is analogous to Figure 4 and shows the seasonal dependence of the average signed differences over land for the four model datasets calculated using Aqua pixels (solid curves). During the boreal summer the four datasets show large negative DT biases between 0.07 and 0.12 (between 30 and $45 \%$ of the global long-term mean AOT). During boreal winter the bias is positive and ranges between 0.05 and $0.16(25-60 \%$ of the global long-term mean). Over land the stronger seasonality is also evident in the ratio of the number of DT pixels to the total number shown in Figure 3(d). Although over ocean this ratio is $\sim 22 \%$ for both MODIS instruments, over land it is generally higher for the MODIS Terra and regularly falls below $10 \%$ for the MODIS Aqua in boreal winter.

Figure 8 shows the long-term global mean AOT calculated using DT pixels of a given MODIS longitudinal track as a function of the track number over land ((a) and (b), solid curves). Dashed lines indicate the 'true' AOT level, calculated using all the MODIS pixels. As in the case of over-the-ocean pixels (Figure 6), the DT bias over land varies strongly with the longitudinal track number and the season. The mean latitude ((c) and (d), solid curves) of the pixels depends significantly on the track number and exhibits a shift of $\sim 5^{\circ}$ between winter and summer. This shift is significantly less pronounced than in the case of the glintaffected tracks over the ocean. It indicates, however, that the weight of various geographical locations in the mean global AOT changes with season, potentially leading to biases. In addition, the possibility of some variations in the cloud-screening procedures with the longitudinal track number cannot be excluded. Such non-uniformity would be implicitly reflected in the number and location of the DT pixels and may lead to seasonal biases. Further research is needed to evaluate the importance of this effect.

The Deep Blue (DB) algorithm (Hsu et al., 2004) improves the ability of the MODIS instrument to retrieve aerosol properties over bright surfaces, such as deserts. As high aerosol loads are
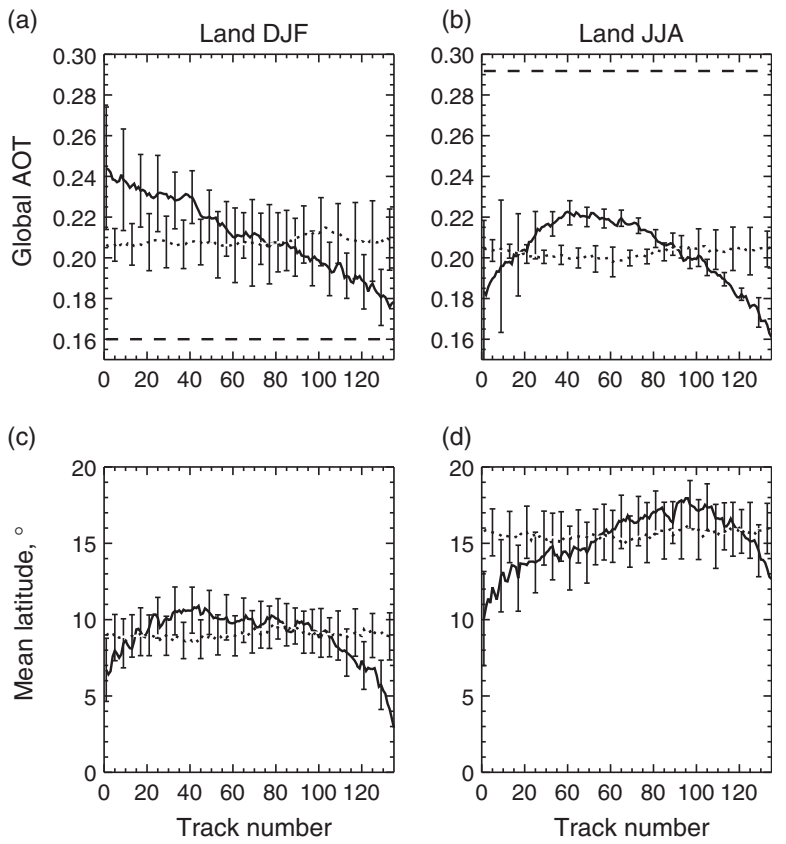

Figure 8. Same as in Figure 6, but over land.

frequent over deserts, we may expect that the addition of the DB pixels to the DT pixels will improve the agreement with the all-pixel global means. The DB + DT curves are shown in Figure 7 by dashed curves: DB retrievals with the QA flag value 3 were used. It can be seen that the addition of the DB pixels tempers the seasonal dependence of the DT-pixel bias and reduces the average absolute difference with the all-pixel case by $\sim 0.01$ to $\sim 0.02$ (compare solid and dashed straight lines in Figure 7).

The effect of the addition of the DB pixels on the AOT PDF can be observed in Figure 5(c,d). During the DJF season (c), DT-only PDF (dotted curve) overestimate the frequency of AOTs greater than 0.1 and underestimate the frequency of AOTs smaller than 0.1 compared with the all-pixel case (solid curve). The addition of the DB pixels improves the agreement for all AOT values. During the boreal summer the DT + DB PDF reduces underestimation of large AOT frequency compared with DT-only case, and the region of overestimation shifts toward smaller AOT values. The observed reduction of biases demonstrates how important it is for a remote sensing instrument to retrieve aerosol properties in the widest range of conditions.

\section{Along-track sensor results}

Following the procedure described in section 2, we partition MODIS pixels into longitudinal and latitudinal sets. For each value of the global monthly mean AOT calculated using all imager pixels we can thus obtain 135 longitudinal track values and 135 latitudinal ones. Given these sets of 135 values, we calculate longitudinal-track and latitudinal-track standard errors. We then find the median value of these standard errors over all months. The results over ocean and over land are summarized in Tables 2 and 3, respectively.

As discussed earlier, single-longitudinal-track estimates of the global mean may systematically differ between each other. These systematic differences will increase the longitudinal standard error over the level caused by the natural aerosol variability. On the other hand, the relative contribution of all imager viewing geometries to each latitudinal track is the same by design. This is demonstrated by Figures 6(a) and (b) and 8(a) and (b), where global mean AOT for latitudinal tracks is shown by dotted curves. Unlike the case of the longitudinal tracks where strong variability is apparent, the latitudinal curves are essentially flat, showing no dependence on the track number. In addition, they show 
Table 2. Longitudinal and latitudinal standard errors of the global monthly mean AOT over ocean for an along-track sensor calculated using the model datasets from Table 1. Relative values (\%) given in parentheses are with respect to the rescaled global mean AOT values from Table 1.

\begin{tabular}{|c|c|c|c|c|}
\hline \multirow[t]{2}{*}{ Model } & \multicolumn{2}{|c|}{ All-pixel standard error } & \multicolumn{2}{|c|}{ DT-pixel standard error } \\
\hline & Longitudinal & Latitudinal & Longitudinal & Latitudinal \\
\hline SPRINTARS-Terra & $0.00063(0.47)$ & $0.00078(0.59)$ & $0.012(11)$ & $0.0015(1.3)$ \\
\hline SPRINTARS-Aqua & $0.00065(0.5)$ & $0.00081(0.61)$ & $0.012(10)$ & $0.0014(1.2)$ \\
\hline GISS-Aqua & $0.0010(0.7)$ & $0.00076(0.54)$ & $0.020(17)$ & $0.0016(1.3)$ \\
\hline GOCART-Aqua & $0.00043(0.33)$ & $0.00050(0.39)$ & $0.016(14)$ & $0.0012(1.0)$ \\
\hline TM5-Aqua & $0.0005(0.4)$ & $0.00087(0.7)$ & $0.022(17)$ & $0.0015(1.2)$ \\
\hline
\end{tabular}

Table 3. Longitudinal and latitudinal standard errors (\% in parentheses) of the global monthly mean AOT over land for an along-track sensor.

\begin{tabular}{|c|c|c|c|c|}
\hline \multirow[t]{2}{*}{ Model } & \multicolumn{2}{|c|}{ All-pixel standard error } & \multicolumn{2}{|c|}{ DT-pixel standard error } \\
\hline & Longitudinal & Latitudinal & Longitudinal & Latitudinal \\
\hline SPRINTARS-Terra & $0.0028(1.3)$ & $0.004(1.78)$ & $0.014(7.2)$ & $0.009(4.6)$ \\
\hline SPRINTARS-Aqua & $0.003(1.3)$ & $0.0043(1.9)$ & $0.018(9.3)$ & $0.0096(4.9)$ \\
\hline GISS-Aqua & $0.0021(1.0)$ & $0.0029(1.4)$ & $0.010(5.3)$ & $0.007(3.7)$ \\
\hline GOCART-Aqua & $0.0029(1.1)$ & $0.0034(1.2)$ & $0.023(8.6)$ & $0.010(3.7)$ \\
\hline TM5-Aqua & $0.003(1.2)$ & $0.0025(1.0)$ & $0.023(8.5)$ & $0.011(4.1)$ \\
\hline
\end{tabular}

little variability in the mean latitude of the pixels (dotted curves on the Figures $6(\mathrm{c})$ and $(\mathrm{d})$ and $8(\mathrm{c})$ and $(\mathrm{d})$ ), meaning that each latitudinal track has a geographical coverage similar to the whole imager set. Owing to these properties, the latitudinal standard error is a better measure of the natural variability. A large discrepancy between the two error measures is indicative of the longitudinal track-to-track differences and it is therefore useful to consider both measures.

In the all-pixel scenario, all angular biases are excluded, because we are using model AOT values. In addition, unlike the DT case, the results are not implicitly affected by the MODIS algorithm's retrieval decisions and cloud mask. We should therefore expect the longitudinal and latitudinal standard errors to be close to each other. An inspection of the relevant columns in Tables 2 and 3 shows that the two error measures are similar for all model datasets. A small excess in the latitudinal variability may be traced to the prevalence of the east-west transport of aerosol plumes in the model data. Future along-track instruments are likely to sample in the direction along the vector of motion. For a Sunsynchronous orbit this direction is close to the north-south line. We may therefore take the median of the longitudinal standard errors of $0.0005(0.5 \%)$ over ocean and 0.0029 (1.1\%) over land as a limit imposed by the sampling on the estimates of the global monthly mean aerosol properties. These lower limit error estimates correspond to the idealized case of an instrument able to retrieve aerosol properties regardless of cloudiness over all surfaces. The median of the ratio of absolute standard errors over land and over ocean is 4.6. One should, however, bear in mind that the average global 6 year mean AOT over land is higher than over ocean (cf. Table 1), so in relative terms the error is about three times larger over land. This most probably reflects the higher variability of aerosol amounts over land due to sources such as deserts and biomass burning. Overall, these alongtrack standard error estimates are several times higher than the differences between the MODIS Terra and Aqua means discussed in the previous section, but are still small.

The last two columns of Tables 2 and 3 represent standard error estimates for an along-track sampling instrument with MODIS-like capabilities. Latitudinal standard errors over land and ocean are about 2.5 higher than the idealized all-pixel values. Unlike the all-pixel case, longitudinal errors are now significantly higher than the latitudinal errors. We have discussed previously the effects that lead to this excess of variability over the natural level (cf. Figures 6 and 8). To work around this problem, we can use latitudinal standard error values to obtain an estimate of the accuracy. The median values over all models are 0.0015 over ocean and 0.01 over land in the absolute sense or 1.2 and $4 \%$ of the corresponding long-term global means. This upper limit estimate corresponds to an along-track sampling sensor with MODIS-like capabilities.

We noted in the preceding section that small-scale variability cannot be accounted for by using the model data. We therefore reapplied the perturbation test described there to see how the values in Tables 2 and 3 would change. For the 30 and $50 \%$ perturbations, we found that the differences between the standard and perturbed cases were within the rounding error of two significant digits. We can therefore expect the estimates discussed above not to change significantly because of subcell AOT variability.

These numbers provide the accuracy estimates due to the limited sampling of an along-track sensor. They are obtained under the assumption that the corresponding imager means are 'true' and do not include the DT biases we discussed in the preceding section. The estimates are somewhat higher than those obtained by Geogdzhayev et al. (2013) using real MODIS Terra AOT data. They are, however, still smaller than or comparable to the estimates published by Hansen et al. (1995) and Loeb and Su (2010), which imply that a change of $\sim 0.01$ in the global AOT can be climatically important. This suggests that the density of the sampling is unlikely to be a factor limiting the use of such instruments for climate applications.

\section{Conclusions}

We used MODIS Aqua and Terra level 2 pixel coordinates together with aerosol data from one GCM and three CTMs to (i) estimate the effects of sampling on the accuracy of global monthly mean AOT inferred from the MODIS retrievals and (ii) obtain a likely range (lower and upper limits) of errors due to sampling of the global mean AOT derived from an along-track remote sensing instrument. The use of model aerosol data in lieu of actual retrieval allowed us to remove the uncertainty associated with possible retrieval algorithm biases and obtain self-consistent AOT estimates not only for locations where actual retrievals were made but also for locations where they were not possible.

We have found that the MODIS tends to underestimate global aerosol mean over ocean with an absolute difference between all and DT pixels of between 0.01 and 0.02 depending on the model dataset. Over land the mean absolute AOT differences are between 0.03 and 0.09 . Negative DT biases are maximal during the boreal summer for all four datasets and can reach values between 0.07 and 0.12 (30-45\% of the global long-term mean AOT). 


\section{Geogdzhayev et al.}

The addition of the DB pixels makes the seasonal dependence of the DT biases smoother and reduces the long-term mean absolute monthly AOT difference by $\sim 0.01$ to $\sim 0.02$.

By partitioning MODIS pixels into single-track subsets, we calculated the standard error due to sampling for global monthly mean AOT retrieved by an along-track sampling sensor such as APS or CALIOP. Considering the cases of all- and DT-only-pixel scenarios, we determined the lower and upper limit estimates of this error. The lower estimate represents the limit imposed by reduced sampling on the accuracy of an idealized sensor capable of retrieving aerosols everywhere regardless of clouds. The upper estimate corresponds to an instrument with MODIS-like capabilities and a cloud-screening algorithm. We found this range to be between 0.5 and $1.1 \%$ (in the relative sense) over ocean and 1.2 and $4 \%$ over land. The actual sampling errors of current (e.g. CALIOP) or future along-track aerosol sensors will depend on their capabilities and may be expected to fall within this range. These numbers are estimates of the global mean AOT errors due to reduced sampling only and do not include the imager biases. In fact, the comparison of the two types of errors suggests that, in terms of climatological accuracy, the limitations imposed on an along-track space-borne aerosol sensor by reduced sampling are less important than its ability to retrieve aerosol properties in a wide range of conditions.

In this study we used daily model data without a daily cycle, whereas space-borne aerosol sensors have fixed overpass times. Thus aerosol diurnal cycle is not included in our error estimates. The results of Kaufman et al. (2000) suggest that globally the effect can be expected to be small $(<2 \%)$ at least for the annual mean AOT.

One of the four anonymous reviewers of this article suggested that the use of daily model data causes overly smooth AOT fields (especially over ocean). As a consequence, the errors we report may be underestimates. Note, however, that for an along-track sensor they are similar to the estimates obtained by Geogdzhayev et al. (2013) using actual MODIS retrievals that have a nominal resolution of $10 \mathrm{~km}$.

We believe our findings are important for assessing the capabilities of current and future space-borne aerosol sensors as well as for using remote sensing aerosol data in model climate studies.

\section{Acknowledgements}

We are grateful to Dr Thomas Diehl for providing GOCART data and to Dr Toshihiko Takemura for providing SPRINTARS data for this study as well as to Li Liu for help with the MODIS Level2 data. We thank four anonymous reviewers whose insightful comments have resulted in a much improved article. This study was supported by the research division of the NASA Glory Mission Project managed by Hal Maring.

\section{References}

Alexandrov MD, Lacis AA, Carlson BE, Cairns B. 2003. Atmospheric aerosol and trace gases parameters derived from local MFRSR network: Multiinstrument data fusion in comparison with satellite retrievals. Proc. SPIE 4882: 498-509.

Alexandrov MD, Marshak A, Cairns B, Lacis AA, Carlson BE. 2004. Scaling properties of aerosol optical thickness retrieved from ground-based measurements. J. Atmos. Sci. 61: 1024-1039.

Bellouin N, Jones A, Haywood J, Christopher SA. 2008. Updated estimate of aerosol direct radiative forcing from satellite observations and comparison against the Hadley Centre climate model. J. Geophys. Res. 113: D10205, doi:10.1029/2007JD009385.

Bellouin N, Quaas J, Morcrette JJ, Boucher O. 2013. Estimates of aerosol radiative forcing from the MACC re-analysis. Atmos. Chem. Phys. 13: 2045-2062.

Bodas-Salcedo A, Webb MJ, Bony S, Chepfer H, Dufresne JL, Klein SA, Zhang Y, Marchand R, Haynes JM, Pincus R, John VO. 2011. COSP: Satellite simulation software for model assessment. Bull. Am. Meteorol. Soc. 92: 1023-1043.

Cairns B, Mishchenko MI. (eds.) 2012. The Need for Aerosol and Cloud Measurements from Space: Essential Contributions from a Rapid Reflight of the Aerosol Polarimetry Sensor. NASA Goddard Institute for Space Studies: New
York, NY. http://glory.giss.nasa.gov/APS-2_Report.pdf (accessed 7 January 2014)

Cairns B, Waquet F, Knobelspiesse K, Chowdhary J, Deuzé JL. 2009. Polarimetric remote sensing of aerosols over land surfaces. In Satellite Aerosol Remote Sensing Over Land, Kokhanovsky AA, de Leeuw G. (eds.): 295-325. Springer: Chichester, UK.

Chowdhary J, Cairns B, Mishchenko MI, Hobbs PV, Cota GF, Redemann J Rutledge K, Holben BN, Russell E. 2005. Retrieval of aerosol scattering and absorption properties from photopolarimetric observations over the ocean during the CLAMS experiment. J. Atmos. Sci. 62: 1093-1118.

Chýlek P, Henderson BG, Lesins G. 2005. Aerosol optical depth retrieval over the NASA Stennis Space Center: MTI, MODIS, and AERONET. IEEE Trans. Geosci. Remote Sens. 43: 1978-1983.

Diner D, Beckert J, Reilly T, Bruegge CJ, Conel JE, Kahn RA, Martonchik JV, Ackerman TP, Davies R, Gerstl SAW, Gordon HR, Muller JP, Myneni RB, Sellers PJ, Pinty B, Verstraete MM. 1998. Multiangle Imaging SptectrRadiometer (MISR) description and experiment overview. IEEE Trans. Geosci. Remote Sens. 36: 1072-1087.

Dubovik O, Holben B, Eck TF, Smirnov A, Kaufman YJ, King MD, Tanré D, Slutsker I. 2002. Variability of absorption and optical properties of key aerosol types observed in worldwide locations. J. Atmos. Sci. 59: 590-608.

Geogdzhayev IV, Cairns B, Alexandrov M, Mishchenko MI. 2013. Statistical analysis of single-track instrument sampling in spaceborne aerosol remote sensing for climate research. J. Quant. Spectrosc. Radiat. Transfer 121: 69-77.

Hansen J, Rossow W, Carlson B, Lacis A, Travis L, Del Genio A, Gung I, Cairns B, Mishchenko M, Sato M. 1995. Low-cost long-term monitoring of global climate forgings and feedbacks. Clim. Change 31: 247-271.

Hansen J, Nazarenko L, Ruedy R, Sato M, Willis J, Del Genio A, Koch D, Lacis A, Lo K, Menon S, Novakov T, Perlwitz J, Russell G, Schmidt GA, Tausnev N. 2005. Earth's energy imbalance: Confirmation and implications. Science 308: $1431-1435$.

Hasekamp OP, Landgraf J. 2005. Retrieval of aerosol properties over the ocean from multispectral single-viewing-angle measurements of intensity and polarization: Retrieval approach, information content, and sensitivity study. J. Geophys. Res. 110: D20207, doi:10.1029/2005JD006212.

Hasekamp OP, Landgraf J. 2007. Retrieval of aerosol properties over land surfaces: Capabilities of multiple-viewing-angle intensity and polarization measurements. Appl. Opt. 46: 3332-3344.

Holben BN, Eck TF, Slutsker I, Tanré D, Buis JP, Setzer A, Vermote E, Reagan JA, Kaufman YJ, Nakajima T, Lavenu F, Jankowiak I, Smirnov A. 1998 AERONET - a federated instrument network and data archive for aerosol characterization. Remote Sens. Environ. 66: 1-16.

Hsu NC, Tsay SC, King MD, Herman JR. 2004. Aerosol properties over brightreflecting source regions. IEEE Trans. Geosci. Remote Sens. 42: 557-569.

Ichoku C, Remer LA, Eck TF. 2005. Quantitative evaluation and intercomparison of morning and afternoon Moderate Resolution Imaging Spectroradiometer (MODIS) aerosol measurements from Terra and Aqua. J. Geophys. Res. 110: D10S03, doi:10.1029/2004JD004987.

Inness A, Baier F, Benedetti A, Bouarar I, Chabrillat S, Clark H, Clerbaux C, Coheur P, Engelen RJ, Errera Q, Flemming J, George M, Granier C, Hadji-Lazaro J, Huijnen V, Hurtmans D, Jones L, Kaiser JW, Kapsomenakis J, Lefever K, Leitão J, Razinger M, Richter A, Schultz MG, Simmons AJ, Suttie M, Stein O, Thépaut JN, Thouret V, Vrekoussis M, Zerefos C, the MACC team. 2013. The MACC reanalysis: An 8 yr data set of atmospheric composition. Atmos. Chem. Phys. 13: 4073-4109.

IPCC. 2007. Summary for policymakers. In Climate Change 2007: The Physical Science Basis, Solomon S, Qin D, Manning M, Chen Z, Marquis M, Averyt KB, Tignor M, Miller HL. (eds.). Cambridge University Press: Cambridge, UK, pp. 1-18.

Kahn R, Nelson D, Garay M, Levy R, Bull M, Diner D, Martonchik JV, Paradise SR, Hansen EG, Remer LA. 2009. MISR aerosol product attributes and statistical comparisons with MODIS. IEEE Trans. Geosci. Remote Sens. 47: 4095-4114.

Kaufman YJ, Holben BN, Tanré D, Slutsker I, Smirnov A. 2000. Will aerosol measurements from Terra and Aqua polar orbiting satellites represent the daily aerosol abundance and properties? Geophys. Res. Lett. 27: 3861-3864, doi:10.1029/2000GL011968.

Kiehl JT. 2007. Twentieth century climate model response and climate sensitivity. Geophys. Res. Lett. 34: L22710, doi:10.1029/2007GL031383.

King MD, Menzel WP, Kaufman YJ, Tanré D, Gao BC, Platnick S, Ackerman SA, Remer LA, Pincus R, Hubanks PA. 2003. Cloud and aerosol properties, precipitable water, and profiles of temperature and water vapor from MODIS. IEEE Trans. Geosci. Remote Sens. 41: 442-458.

Kinne S, Schulz M, Textor C, Guibert S, Balkanski Y, Bauer SE, Berntsen T, Berglen TF, Boucher O, Chin M, Collins W, Dentener F, Diehl T, Easter R, Feichter J, Fillmore D, Ghan S, Ginoux P, Gong S, Grini A, Hendricks J, Herzog M, Horowitz L, Isaksen I, Iversen T, Kirkevåg A, Kloster S, Koch D, Kristjansson JE, Krol M, Lauer A, Lamarque JF, Lesins G, Liu X, Lohmann U, Montanaro V, Myhre G, Penner J, Pitari G, Reddy S, Seland O, Stier P, Takemura T, Tie X. 2006. An AeroCom initial assessment -optica properties in aerosol component modules of global models. Atmos. Chem. Phys. 6: 1815-1834.

Knobelspiesse K, Cairns B, Mishchenko M, Chowdhary J, Tsigaridis K, van Diedenhoven B, Martin W, Ottaviani M, Alexandrov M. 2012. Analysis of fine-mode aerosol retrieval capabilities by different passive remote sensing instrument designs. Opt. Express 20: 21457-21484.

Levy RC. 2009. The dark-land MODIS collection 5 aerosol retrieval: Algorithm development and product evaluation. In Satellite Aerosol Remote Sensing 
Over Land, Kokhanovsky AA, de Leeuw G. (eds.): 19-68. Praxis: Chichester, UK.

Levy RC, Remer LA, Kleidman RG, Mattoo S, Ichoku C, Kahn R, Eck TF. 2010. Global evaluation of the collection 5 MODIS dark-target aerosol products over land. Atmos. Chem. Phys. 10: 10399-10420.

Loeb NG, Su W. 2010. Direct aerosol radiative forcing uncertainty based on a radiative perturbation analysis. J. Clim. 23: 5288-5293.

Lohmann U, Ferrachat S. 2010. Impact of parametric uncertainties on the present-day climate and on the anthropogenic aerosol effect. Atmos. Chem. Phys. 10: 11373-11383.

Martonchik JV, Kahn RA, Diner DJ. 2009. Retrieval of aerosol properties over land using MISR observations. In Satellite Aerosol Remote Sensing Over Land, Kokhanovsky AA, de Leeuw G. (eds.): 267-293. Praxis: Chichester, UK.

Meister G, Franz BA, Kwiatkowska EJ, McCain CR. 2012. Corrections to the calibration of MODIS Aqua ocean color bands derived from SeaWiFS data. IEEE Trans. Geosci. Remote Sens. 50: 310-319.

Mishchenko M, Cairns B, Hansen J, Travis L, Burg R, Kaufman YJ, Martins V, Shettle V. 2004. Monitoring of aerosol forcing of climate from space: Analysis of measurement requirements. J. Quant. Spectrosc. Radiat. Transfer 88: $149-161$.

Mishchenko MI, Cairns B, Kopp G, Schueler CF, Fafaul BA, Hansen JE, Hooker RJ, Itchkawich T, Maring HB, Travis LD. 2007. Accurate monitoring of terrestrial aerosols and total solar irradiance: Introducing the Glory Mission. Bull. Am. Meteorol. Soc. 88: 677-691.

Mishchenko MI, Geogdzhayev IV, Liu L, Lacis AA, Cairns B, Travis LD. 2009. Toward unified satellite climatology of aerosol properties: What do fully compatible MODIS and MISR aerosol pixels tell us? J. Quant. Spectrosc. Radiat. Transfer 110: 402-408.

Mishchenko MI, Liu L, Geogdzhayev IV, Travis LD, Cairns B, Lacis AA. 2010. Toward unified satellite climatology of aerosol properties. 3. MODIS versus MISR versus AERONET. J. Quant. Spectrosc. Radiat. Transfer 111: 540-552.

Myhre G, Samset BH, Schulz M, Balkanski Y, Bauer S, Berntsen TK, Bian H, Bellouin N, Chin M, Diehl T, Easter RC, Feichter J, Ghan SJ, Hauglustaine $\mathrm{D}$, Iversen T, Kinne S, Kirkevåg A, Lamarque JF, Lin G, Liu X, Lund MT, Luo G, Ma X, van Noije T, Penner JE, Rasch PJ, Ruiz A, Seland $\varnothing$, Skeie RB, Stier P, Takemura T, Tsigaridis K, Wang P, Wang Z, Xu L, Yu H, Yu F, Yoon JH, Zhang K, Zhang H, Zhou C. 2013. Radiative forcing of the direct aerosol effect from AeroCom Phase II simulations. Atmos. Chem. Phys. 13: $1853-1877$.

Penner JE, Xu L, Wang M. 2011. Satellite methods underestimate indirect climate forcing by aerosols. Proc. Natl. Acad. Sci. U.S.A. 108: 13404-13408.

Remer LA, Kaufman YJ, Tanré D, Mattoo S, Chu DA, Martins JV, Li RR, Ichoku C, Levy RC, Kleidman RG, Eck TF, Vermote E, Holben BN. 2005. The MODIS aerosol algorithm, products, and validation. J. Atmos. Sci. 62: 947-973.

Remer L, Kaufman YJ, Kleidman RG. 2006. Comparison of three years of Terra and Aqua MODIS aerosol optical thickness over the global oceans. IEEE Geosci. Remote Sens. Lett. 3: 537-540.
Remer L, Kleidman RG, Levy RC, Kaufman YJ, Tanré D, Mattoo S, Martins JV, Ichoku C, Koren I, Yu H, Holben BN. 2008. Global aerosol climatology from the MODIS satellite sensors. J. Geophys. Res. 113: D14S07, doi:10.1029/2007JD009661.

Schulz M, Textor C, Kinne S, Balkanski Y, Bauer S, Berntsen T, Berglen T, Boucher O, Dentener F, Guibert S, Isaksen ISA, Iversen T, Koch D, Kirkevåg A, Liu X, Montanaro V, Myhre G, Penner JE, Pitari G, Reddy S, Seland Ø, Stier P, Takemura T. 2006. Radiative forcing by aerosols as derived from the AeroCom present-day and pre-industrial simulations. Atmos. Chem. Phys. 6: 5225-5246.

Schulz M, Chin M, Kinne S. 2009. The Aerosol Model Comparison Project, AeroCom, Phase II: Clearing up diversity. IGACtivities Newslett. 41: $2-11$.

Schutgens NAJ, Nakata M, Nakajima T. 2013. Validation and empirical correction of MODIS AOT and AE over ocean. Atmos. Meas. Tech. Discuss. 6: $3765-3818$.

Shi Y, Zhang J, Reid JS, Holben B, Hyer EJ, Curtis C. 2011. An analysis of the collection 5 MODIS over-ocean aerosol optical depth product for its implication in aerosol assimilation. Atmos. Chem. Phys. 11: $557-565$.

Shi Y, Zhang J, Reid JS, Hyer EJ, Hsu NC. 2013. Critical evaluation of the MODIS Deep Blue aerosol optical depth product for data assimilation over North Africa. Atmos. Meas. Tech. 6: 949-969.

da Silva A, Colarco P, Darmenov A, Buchard-Marchant V, Randles C, Govinaradju V. 2012. 'Overview of the MERRA aerosol reanalysis: Toward an integrated earth system analysis'. In 4th WCRP International Conference on Reanalyses, Silver Spring: Maryland, MD. http://gmao.gsfc. nasa.gov/pubs/docs/da\%20Silva489.pdf (accessed 7 January 2014).

Takemura T, Nozawa T, Emori S, Nakajima TY, Nakajima T. 2005. Simulation of climate response to aerosol direct and indirect effects with aerosol transport-radiation model. J. Geophys. Res. 110: D02202, doi: 10.1029/2004JD005029.

Tanré D, Bréon FM, Deuzé JL, Dubovik O, Ducos F, François P, Goloub P, Herman M, Lifermann A, Waquet F. 2011. Remote sensing of aerosols by using polarized, directional and spectral measurements within the A-Train: The PARASOL mission. Atmos. Meas. Tech. 4: 1383-1395.

Winker DM, Pelon J, Coakley JA Jr, Ackerman SA, Charlson RJ, Colarco PR, Flamant P, Fu Q, Hoff RM, Kittaka C, Kubar TL, Le Treut H, McCormick MP, Mégie G, Poole L, Powell K, Trepte C, Vaughan MA, Wielicki BA. 2010. The CALIPSO Mission: A global 3D view of aerosols and clouds. Bull. Am. Meteorol. Soc. 91: 1211-1229.

Xiao N, Shi T, Calder CA, Munroe DK, Berrett C, Wolfinbarger S, Li D. 2009. Spatial characteristics of the difference between MISR and MODIS aerosol optical depth retrievals over mainland Southeast Asia. Remote Sens. Environ. 113: 1-9.

Zhang J, Reid JS. 2006. MODIS aerosol product analysis for data assimilation: Assessment of over-ocean level 2 aerosol optical thickness retrievals. J. Geophys. Res. 111: D22207, doi:10.1029/2005JD006898. 